\title{
Ethical dilemmas faced by hospice nurses when administering palliative sedation to patients with terminal cancer
}

\author{
KAY DE VRIES PH.D., M.SC., P.G.C.E.A., B.SC. (HONS.), R.N., ${ }^{1}$ AND \\ MAREK PLASKOTA, M.SC., B.SC. (HONS.), R.G.N. ${ }^{2}$ \\ ${ }^{1}$ School of Health Sciences, University of Brighton, Brighton, England, United Kingdom \\ ${ }^{2}$ St. George's Healthcare National Health Service Trust, St. George's Hospital, Tooting, London, England, United \\ Kingdom
}

(RECEIVEd October 2, 2015; AcCEPTEd May 12, 2016)

\begin{abstract}
Objective: Palliative sedation is a method of symptom management frequently used in hospices to treat uncontrolled symptoms at the end of life. There is a substantial body of literature on this subject; however, there has been little research into the experiences of hospice nurses when administering palliative sedation in an attempt to manage the terminal restlessness experienced by cancer patients.

Method: Semistructured interviews were conducted with a purposive sample of seven hospice nurses who had cared for at least one patient who had undergone palliative sedation within the past year in a hospice in the south of England in the United Kingdom. A phenomenological approach and Colaizzi's stages of analysis were employed to develop themes from the data.

Results: Facilitating a "peaceful death" was the primary goal of the nurses, where through the administration of palliative sedation they sought to enable and support patients to be "comfortable," "relaxed," and "calm" at the terminal stage of their illness. Ethical dilemmas related to decision making were a factor in achieving this. These were: medication decisions, "juggling the drugs," "causing the death," sedating young people, the family "requesting" sedation, and believing that hospice is a place where death is hastened.

Significance of results: Hospice nurses in the U.K. frequently encounter ethical and emotional dilemmas when administering palliative sedation. Making such decisions about using palliative sedation causes general discomfort for them. Undertaking this aspect of care requires confidence and competence on the part of nurses, and working within a supportive hospice team is of fundamental importance in supporting this practice.
\end{abstract}

KEYWORDS: Terminal restlessness, Palliative sedation, Ethical dilemmas, Peaceful death, Hospice nurses

\section{INTRODUCTION}

Refractory symptoms, defined as symptoms that cannot be adequately controlled despite aggressive efforts to identify a tolerable therapy that does not compromise consciousness (Cherny \& Portenoy, 1994), are common in patients with advanced cancer

Address correspondence and reprint requests to: Kay de Vries, Deputy Head of School of Health Sciences, University of Brighton, Westlain House, Village Way, Falmer, Brighton BN1 9PH, England, United Kingdom. E-mail: 1.k.devries@brighton.ac.uk. or other advanced diseases. Expressions such as "terminal restlessness," "terminal delirium," and "terminal agitation" are used interchangeably throughout the literature. For the purposes of the present paper, the term "terminal restlessness" will be employed to describe this symptom. Terminal restlessness can develop days or even weeks before death and manifests in such persistent distressing physical symptoms as pain, breathlessness, and agitated delirium (de Graeff \& Dean, 2007; Morita et al., 2005; Fainsinger et al., 2000). Patients may also experience such 
psychological and spiritual/existential symptoms as severe anxiety, anguish, and fear (Boston et al., 2011; Lavoie et al., 2008). The most common approach taken to ameliorate terminal restlessness is the provision of "terminal or palliative sedation." The European Association for Palliative Care considers the use of sedation to be an important and often necessary symptom management measure in the care of palliative care patients who are experiencing uncontrollable symptoms that cause terminal restlessness (Hauser \& Walsh, 2009; Cherny \& Radbruch, 2009; de Graeff \& Dean, 2007). Large differences in defining palliative sedation are reported in the literature, as is reporting on the frequency of symptoms and sedation practices between countries and services. These are influenced by the country, context, and clinical setting or site at which a study was conducted (de Graeff \& Dean, 2007; Beel et al., 2002). There are also many inconsistencies with regard to the prevalence and effect of sedation, food and fluid intake, and the possible life-shortening effect of palliative sedation (Claessens et al., 2008).

\section{BACKGROUND}

Reporting on the types of medication used and the frequency of the use of palliative sedation for patients at the end of life also varies considerably across the globe. Seale (2009) found that prescription of opioids alone for palliative sedation occurred in a fifth of the cases in the U.K. but was not reported by specialists in palliative care. In $83 \%$ of cases from a study in the Netherlands by Rietjens et al. (2008), sedation was induced by benzodiazepines, often combined with morphine. Benzodiazepines such as midazolam were more likely to be used by palliative care specialists, a practice supported by most guidelines (Rietjens et al., 2008). Levomepromazine (a phenothiazine antipsychotic) and haloperidol (a butyrophenone antipsychotic) are frequently prescribed in palliative care for severe delirium/agitation during the last days of life (Watson et al., 2009). Phenobarbitone is primarily used for terminal sedation in intensive care units and is rarely utilized in hospice, except under circumstances when a terminally agitated patient has not responded to a previous drug regime (Gillon et al., 2010; Cheng et al., 2002). A study in the Netherlands by Swart et al. (2012) comparing palliative sedation for cancer and noncancer patients reported that cancer patients were significantly more likely to receive palliative sedation than noncancer patients. The researchers speculated that this was probably due to the less predictable course of noncancer diseases.

Although evidence-based clinical guidelines have been proposed to manage symptoms in terminally ill patients, clinicians regularly encounter ethical dilemmas when administering palliative sedation (Materstvedt \& Bosshard, 2009, Morita et al., 2003; 2004). It has been shown that in some clinical situations where palliative sedation is required, health professionals experience severe distress due to the suffering of patients and their families, particularly if there is limited success in managing symptoms and decision making has been ambiguous (Brajtman et al., 2006; Morita, 2004; Morita et al., 2004; Fainsinger et al., 2000; Hallenbeck, 2000). Brajtman (2003; 2005) argued that, although it is understood that the use of palliative sedation for terminal restlessness can have a profound effect on a patient's family, little is known about its impact on the team of healthcare professionals.

In a study of 16 nurses' experiences and their attitudes about administering palliative sedation in hospital settings in the Netherlands, sedation was used primarily to address physical suffering in severely ill patients. The nurses differed in how they perceived the effects of palliative sedation on their patients. Some believed it may have had a life-shortening effect and in some cases was justified in the interests of comfort measures, while others thought it did not shorten life and a third group believed that it was close to euthanasia and had difficulty being involved with the practice (Rietjens et al., 2007). A survey of 250 nurses in Flanders (Belgium) about their most recent case of palliative sedation at the end of life reported that $77 \%$ of nurses saw it mainly as a practice intended to hasten death, and they believed that palliative sedation had a life-shortening effect (Inghelbrecht et al., 2011). Only $4 \%$ believed that it had actually had no life-shortening effect. It was also reported that nurses frequently made decisions to start continuous palliative sedation jointly with physicians and that physicians and patients' relatives frequently made decisions without the patient having a role in the decision-making process. In contrast, a prospective longitudinal study of sedation with 266 patients in Flemish palliative care units by Claessens et al. (2011) showed that in all cases patients gave consent to start palliative sedation. Nilsson and Tengvall (2013) interviewed 14 nurses in a specialist palliative care unit in Sweden and identified ethical concerns and also issues related to responsibility, confidence, communication, and teamwork. A study in Scotland by Zinn and Moriarty (2012) of the experiences of nurses carrying out palliative sedation identified three themes-suffering, courage, and peace-as representing how nurses believed that palliative sedation was sometimes necessary and appropriate to ensure a peaceful death.

Seymour and colleagues (2007) conducted interviews with 14 nurses, 11 doctors, and 10 researchers. This research took place in the context of attention to 
euthanasia and assisted dying dialogues in the Netherlands, Belgium, and the U.K. Interview data from clinicians (doctors and nurses) revealed that the administration of palliative sedation required palliative care expertise, collaborative decision-making processes and support systems, a good understanding of the ethical and legal frameworks, and correct interpretation of suffering (Seymour et al., 2007).

A study by Raus et al. (2014) that included the same three countries as above focused on the emotional impact of involvement in continuous sedation by nurses, physicians, and relatives and their understanding of their moral responsibility. Interviews were conducted with 57 physicians, 73 nurses, and 34 relatives. The settings from which participants were recruited were: home, hospitals (mostly oncology wards), and specialist palliative care settings (including hospices). The emotional and moral impact of continuously sedating a patient until death was linked to how emotionally and physically close the participants felt to the patient. Two types of closeness were identified: "decisional closeness," referring to how close the participant felt to the patient, and "causal closeness," the perceived closeness to the causal events of administering sedation. The researchers also identified a theme of "stressing benefits over harms," where participants employed a type of "balancing" reasoning to enable them to cope with their feelings of moral responsibility.

The need for robust processes of ethical decision making was also identified by Dean et al. (2014) following a retrospective review of patient records over a 12-month period in 2009 at a Scottish hospice. The authors identified inconsistencies and a lack of clarity on what constituted "intolerable" or "refractory" suffering and proposed that the patient's ability to consent should be explicitly recorded, that the team have a shared and explicit understanding of the terminology and definitions of sedation, and that formal mechanisms for support (such as clinical supervision) are offered to staff. The development of guidelines has become a focus and priority due to concerns and uncertainty surrounding decisionmaking dilemmas and the connotations and inferences related to euthanasia and palliative sedation (Abarshi et al., 2014; Schildmann \& Schildmann, 2014; Cherny \& Radbruch, 2009; Hauser \& Walsh, 2009; Legemaate et al., 2007; Verkerk et al., 2007; de Graeff \& Dean, 2007; Engström et al., 2006).

The above studies on nurses' experiences offer some insight into the ethical issues that nurses face when administering palliative sedation; however, only a small sample of participants worked exclusively in hospice, and ethical dilemmas across all settings were not largely addressed but did emerge.

\section{RESEARCH DESIGN}

A phenomenological approach was adopted in undertaking our study. Phenomenology focuses on an individual's meaning-making as the key element of the human experience and assumes that there is an underlying structure and core meaning to shared experiences and that these can be described, explained, and interpreted (Patton, 2002). These meanings are not always apparent to participants, so that researchers have to interpret them from participants' narratives (Lopez \& Willis, 2004). An interpretive approach was taken that examined the subjective experiences of the nurses with respect to palliative sedation (Koch, 1995). This was informed by the ideas of Heidegger (1962), who argued that the focus of phenomenological inquiry should be the relationship that the individual has to his or her lifeworld and how participants are being-in-the-world.

Semistructured interviews were carried out with a purposive sample of seven hospice nurses who had cared for at least one patient who had undergone palliative sedation within the past year at a hospice in the south of England. Some 20 nurses working at the hospice were invited to participate in the study, but only 7 responded. All participants were female. Their ages ranged from 24 to 62 , with a median of 43 years. The length of time they had worked in palliative care ranged from 7 months to 8 years.

Sample sizes in qualitative studies are usually small, as the focus is to improve our understanding of complex human issues rather than the generalizability of findings (Patton, 2002; Parahoo, 2006; Creswell, 2009). Interviews followed a phenomenological approach of asking participants to relate specific situations where they had been involved in palliative sedation of a patient at the hospice and how they had felt about this. We used prompts to probe about the types of medication used and for details on administrative practices. Data analysis commenced with the first interview, and no new themes were emerging after carrying out analysis of six interviews. A further interview was conducted that confirmed saturation within seven interviews (Guest et al., 2006), and no new themes emerged. Colaizzi's (1978) stages of analysis were utilized to develop themes from the data. As per Colaizzi's stage seven, all participants were offered the opportunity to comment on both the transcripts and then the developing themes, but all declined. We followed the five expressions from a framework for evaluating rigor in phenomenology developed by de Witt and Ploeg (2006), in tandem with Colaizzi's stages, thus addressing the last stage of Colaizzi's framework, where we drew on our own clinical experience and those of four colleagues who had not been participants in 
the study. In our analysis, we believe we achieved a high level of rigor using the framework of de Witt and Ploeg (2006), where we: (1) established a balance between the voices of study participants and our own philosophical explanations for their experiences, which were underpinned by the concept of a good death; (2) followed an open and systematic process using Colaizzi's framework; (3) determined that the study findings are useful to practice; and (4) found that they resonate with the experiences of other nurses in hospice practice, as addressed above. Actualization of the findings and implications for future practice within hospice care are addressed later in this article.

Ethical approval for the study was obtained from the university ethics committee and the hospice research committee, and written consent was obtained prior to each interview.

\section{FINDINGS}

Facilitating a "peaceful death" was interpreted as the primary purpose of administering palliative sedation to a dying person in the hospice. This interpretation was made based on the language used by the nurses, where they sought to enable and support patients to be "at peace," "settled," "comfortable," "relaxed," and "calm" as they approached death. Achieving this state was underpinned by a number of concerns, interpreted as ethical "dilemmas of care." The dilemmas encountered included: medication decisions, "juggling the drugs," concern that they (the nurses) had caused the death, sedating young people, requests for sedation from family and patients, and relatives conceptualizing hospice as a place where death is hastened. There was a fundamental need for team support in decision making and emotionally managing the difficult and complex situations that were encountered by the nurses.

\section{Facilitating a Peaceful Death}

Central to the nurses' work in managing terminal restlessness was the need to facilitate a "peaceful death." They wanted to see their patients "at peace," "settled," "comfortable," "relaxed," and "calm," as did (according to the nurses) family members. These terms were found repeatedly throughout the data, always related to the aim of the intervention.

\section{Decision Making and Ethical and Emotional Conflict}

\section{Medication Decisions: "Juggling the Drugs"}

Dilemmas occurred most frequently in relation to deciding what drugs to give. All patients referred to by participants had terminal cancer, and midazolam was most frequently the first-line medication given. Concerns were often more specifically about juggling the specific drugs and dose levels in tandem with repeatedly assessing the condition of the patient:

After midazolam, when you give an extra dose and it doesn't work, then I would give levo to help. (N2:15-19)

All of the nurses were troubled at some stage by whether or not they had made the right decision in starting a particular medication:

But when he was restless and you are jumping from one medication to- from midazolam to haloperidol (haloperidol was tried as well), to levomepromazine, obviously, that was the unsettled period when whatever we were trying was not controlling the symptom, and he was still uncomfortable ... that's when we felt unsure. (N3:141-146)

Three of the nurses had the experience of administering phenobarbitone to induce deep continuous sedation. When it was employed, it was the subject of long discussions and debate within the multidisciplinary team. It was also reflected on at length by the participants, both at the time they were involved in the administration and during the interview:

We obviously excluded all the possible reasons for him to be restless, and it was a lot of drugs that we tried to use. We started with midazolam. ... He was even more agitated and restless, and we had to use levomepromazine. In the end, he ended up with two syringe drivers. The second syringe driver was with phenobarbitone, quite a high dose. He died peacefully in the end, but obviously he was very restless before we could get the right dose. (N3:27-31)

When using medications such as phenobarbitone, if the time was protracted before death occurred, the nurses started to doubt their original decision to begin palliative sedation. They expressed concerns that maybe they had missed a reversible cause of the symptom they were trying to manage. This was even more of a concern and dilemma when they became aware of family member discomfort about the length of time that the person remained heavily sedated:

He became very agitated and distressed. Despite trying to exclude all other possible causes, it was difficult to get on top of that symptom, and a decision was made to escalate his treatment, and he 
eventually had a syringe with phenobarbitone. He subsequently died comfortably, but there were some challenges throughout that end-of-life period that might have been in excess of five days on phenobarbitone driver, where certainly the daughters became a little uncertain in their decision-making process, which made it difficult just to be consistent as a team that what we were doing was correct and in the best interest of this patient. (N5:28-36)

\section{'Causing the Death'}

All of the nurses expressed uncertainty that palliative sedation could or would actually lead to the death of the patient, and they repeatedly reflected on this possibility. They all reported experiencing anxiety at some time about such an outcome, but all maintained the position of wanting what was deemed "best for the patient" at that time. The more experienced nurses expressed higher confidence in their decisions to administer palliative sedation, balancing this with the aim of the intervention:

Although I would never be sure whether the medications had hastened the patient's death. I am always clear in my mind that my aim is to- is the patient's comfort or perhaps to control extreme agitation, or distress. (N5:11-15)

We had to give this gentleman quite a large dose of levomepromazine before we got him settled. And he did settle. He did die afterwards, I think within hours, which proves to me that it was very, very terminal agitation. It was a very large dose of levo that we had to give. And we did not give it all in once. Obviously, we went in, and when it didn't work, we went in again. I feel that was appropriate. (N1:45-51)

They took their responsibilities very seriously, and all expressed concern about whether or not their actions were ethically sound. Each experience added to their growing expertise on administration of palliative sedation, and their decisions were always carefully considered from a number of angles and perspectives:

I had a patient who was very frightened about dying and just wanted to be given a midazolam syringe driver for last few weeks of his life, and I felt that that was not ethically right, as he was still able to eat and drink, and by sedating him to that level, we would be actually hastening his death because it would be preventing him from eating and drinking, and he would be left in bed ... and more prone to chest infections, which could hasten his death. ... That's always been something that stayed in my mind. Therefore, I am very careful about the use of the drug and don't think that, in most cases, in any cases really, that using midazolam has hastened death. (N6:128-137)

\section{Sedating Young People}

The patient's age was a significant factor that led to dilemmas about using palliative sedation. Feelings and concerns regarding the impact of palliative sedation were more powerful if the dying person was younger. All of the nurses found it more difficult to sedate younger patients and worried that they might be missing a reversible cause of the agitation. It was particularly problematic if it was an unexpected event:

I never dealt with terminal restlessness presenting in such an aggressive way in such a young person with such a young family and with the family being so distraught about it. I felt anxious about administering big doses to somebody who was still young and ... he deteriorated very suddenly from somebody who was able to stand and get himself to bed ... and in a couple of days he had a rapid disease progression. So it made me feel anxious about administering ... at that point, because generally people are probably comatose and look cachectic? ... but he still looked facially ... and in his body ... he didn't look that ill. That's probably what made me feel so different about doing it. (N4:110-120)

When the patient was younger, relatives were often overwhelmed by the rapid changes they saw in the dying person's condition and behavior. These rapid changes were frequently the reason why the patient had been admitted to the hospice. Family members regularly indicated their sense of helplessness and expressed a desire for the professionals to take control of the situation:

Basically, [the patient's wife] just wanted us to take control of the situation. She didn't have any great views or opinions about what we were doing. She was just happy she had professionals to help her with the situation. (N1:79-82)

This sense of helplessness was also experienced by the nurses, causing them to become cautious in their approaches to administering palliative sedation:

I hadn't seen that sort of thing before, and so, and she looked terrified, absolutely terrified, and the children were just sort of looking to me. You know, can't you do something? And I just felt out of my depth. So I was going in with like 2.5 
midazolam, really scared to up it, whereas now I wouldn't hesitate, and if 2.5 didn't help, then I'd be going in with something else, but then it was just- I just, it felt hopeless really. (N7:34-43)

It was often the sense of helplessness and hopelessness that led patients and families to make requests for palliative sedation to be activated. However, requests related to terminal restlessness were predominantly made by family members, as the patients themselves were usually incapable of making such requests.

\section{Requests for Sedation and Believing that Hospice Was a Place Where Death Is Hastened}

Care dilemmas were closely interrelated to providing support for families as well as the patient and being torn between having the responsibility to attend to the needs of both. The nurses recognized the difficulties faced by families, and dealing with family distress impacted on how care was managed. In many situations, when family members said that they just wanted their loved ones "to be comfortable," it was implicitly understood, and often explicitly expressed, that they wanted the patient sedated and did not want to be exposed to their restless and agitated behavior:

They were desperate for it. It wasn't that they haven't thought of [sedation], and we put it to them as an idea. It was more that they were desperate. They were so upset by seeing their loved one distressed by what was happening to him and so out of character and so aggressive that they wanted also what was the best thing for him, and that was for him to be settled and out of the distress and discomfort that he was in. They were almost begging for us to do something ... "please calm him down." (N4:81-88)

The views about hospice practice held by some relatives were distressing to the nurses: "They think that nobody ever goes home." These related to comments which intimated that family members believed that hospice nurses can, and do, intentionally hasten a patient's death at times. When they had to deal with overt requests from family members to accelerate a patient's death, they were often shocked that the implications were that they would be prepared to actually hasten the death:

She thought we were giving him an injection to finish him off, and I found that quite scary. When we talked her through, she was fine, but, you know, it's not very nice if somebody, even just for a second, would think that. (N1:114-116)
This was not the situation for many family members who wanted sedation. The majority were simply relieved to see their loved ones peaceful and no longer agitated or appearing to be at risk of damaging themselves. This enabled them to make the most of the time they had left with the patient:

Once he was sedated, they were actually able to spend a lot of quality time together. They played music that they played at their wedding, and he was so much [more] peaceful. She laid on the bed with him, and she slept in the room. And because he was in this state rather than the aggressive one, they were able to spend a few days of some quality time together without his last day of his life being agitated and aggressive. ... He was settled and peaceful. And they had that room so comfortable in there. They had a lot of time and space together. (N4: 232-242)

However, one of the more senior nurses admitted that she found not being able to discuss treatment options with the patient ethically challenging. This was frequently due to advanced disease causing the patient to be unable to communicate as a result of delirium and the agitation and disorientation that this caused:

It would become an ethical dilemma if, if you really can't discuss it with the patient properly, so you try to explain it to the family, and it depends where the family are at. We need to remember we are treating the patient not the family. (N3, 198-201)

\section{"Being Supported"}

The importance of support when making decisions about administering palliative sedation was heavily emphasized. This included having opportunities to share the decision making with team members. They were relieved at having somebody more senior, such as the ward manager or a palliative consultant, confirm that administering sedation was the right decision to make. It was seen as part of the supportiveness of working with an experienced palliative care team:

It was so upsetting as well to nurse a man and his family through such a difficult time. It was felt through the whole ward really. So the manager was always around offering support ... very approachable and offering reassurance as well that we were doing everything for the best of the patient. (N2:134-140)

One newly qualified nurse admitted to being very frustrated when she felt out of her depth and could 
not find anybody on the ward to talk to, from whom to seek advice:

Because I wasn't getting anywhere with what I was giving her, I was, like I say, I was out of my depth at that time ... it was one of those occasions where I needed a lot of reflection because I felt I let her down because of my inexperience. (N7:63-64, 92-93)

Being praised for "doing a good job" was also perceived by the nurses as a form of support. It reassured them that their actions were acknowledged and approved regardless of whether it came from the management or the relatives, or it was stated during reflective practice sessions:

[The palliative care team] felt that I had done a good, as good job as I could and were appreciative for what I had done, so that was - that made me feel better about it. I felt upset about it, but I think they felt I had done my best. I know I shouldn't think about how I feel, but actually somehow it made it better for me afterwards. (N6:102-106)

\section{DISCUSSION}

The key finding of our study was that the nurses believed that administration of palliative sedation facilitated a "peaceful death" for dying patients. However, achieving this led to "dilemmas of care" for the nurses concerned. Our finding that the nurses wanted to see their patients "at peace," "settled," "comfortable," "relaxed," and "calm" is in keeping with the findings of Zinn and Moriarty (2012), in that hospice nurses believed patients suffered and were rendered peaceful by palliative sedation.

The concept of a peaceful death is concordant with that of the "good death," a term that has been central to the hospice movement (Hart et al., 1998) and is a subject that has attracted a number of research projects and considerable philosophical dialogue. There has been criticism of attempts to establish what could be considered a good death due to the vast diversity of individual values and preferences and a growing consensus that a good death is something that cannot be defined beforehand in general terms and is not the same for everyone (Goldsteen et al., 2006, McNamara, 2004). We acknowledge the above (and many other) discussions on this concept and also the claim by Scarre (2012) that the expression "good death" is necessarily an oxymoron. However, the "peaceful death" referred to by the nurses was consistent with the more pragmatic conceptualization of good and bad deaths by Low and Payne (1996), for whom a "good" death was deemed to be adequate symptom management resulting in a patient's comfort and lack of family distress, while a "bad" death was the result of uncontrolled symptoms, lack of acceptance, or being young.

All of the patients discussed by the participants had cancer, confirming that this patient group is the most likely to receive palliative sedation (Swart et al., 2012). Medications that were used were consistent with those identified in the literature as most likely to be utilized by specialist palliative clinicians. All of the nurses demonstrated knowledge and expertise in the range of medications used and their efficacy in palliative sedation. The medication that caused a significant dilemma was phenobarbitone, which is an anticonvulsant mainly used in intensive care units to induce long-term sedation to enable mechanical ventilation. The rarity of the use of phenobarbitone in hospice (Gillon et al., 2010; Cheng et al., 2002) was reflected in the concerns expressed by nurses when administering it.

Managing terminal restlessness in patients with advanced disease is essential. Some even describe it as a "moral imperative" and argue that there is no need for it to be such an ethically controversial issue (Kohara et al., 2005). This does not lessen the emotions experienced by those who are closely involved in making decisions, interacting closely with the patients and family members and actually administering the medications (Morita et al., 2004; Zinn \& Moriarty, 2012; Rau et al., 2014). Brajtman (2003) found that families experienced multidimensional suffering and could be ambivalent about sedating medications, feeling that they "were being pulled in two different directions" (p. 457). They wanted the patient's suffering to end but also wanted to continue to be able to communicate with them (Brajtman, 2003). These were reactions reported by the nurses in our study, although there was emphasis on the family desire for sedation rather than not. Our data also revealed a strong focus on experiences related to decision-making dilemmas specific to the type of medications that were used rather than perceptions about the experiences of family members, which was the focus of the participants in the Zinn and Moriarty study (2012). This is perhaps a reflection of the details of what and how medications were used that we asked about during interviews.

Some relatives were reported as holding views about hospice practice that were shocking and unexpected-that is, the belief that hospice nurses can, and do, intentionally hasten a patient's death at times. This was the conclusion drawn by Seymour et al. (2007), who found that U.K. clinicians (nurses included) had to deal with "paradoxical and potentially contradictory cultural meanings associated with the methods used to relieve suffering" 
(p. 1683). As also found in our study, in some instances the nurses found that the act of administering sedation for terminal restlessness was interpreted as "attempts to hasten death" (Seymour et al., 2007).

Dealing every day with dying people requires exceptional personal qualities. However, Kulbe (2001) argues that even the nurses in possession of those qualities are affected by the emotional burden of their work and are at risk of burnout, which will affect the quality of care they provide. The hospice movement is well known for its supportiveness toward patients, their families, and friends as well as staff. Support is particularly strong in relation to making difficult and ethically challenging decisions where sharing knowledge and support are seen as important components of an effectively working healthcare team (Kirklin, 2010; Fillion et al., 2007). The nurses in our study generally felt supported by the hospice team in decision making and in emotionally managing the difficult and complex situations that they encountered when administering palliative sedation. Furthermore, there was a recognition that high-level decision making required experience, specialist skills, and consultation with team members, a finding upheld by other research (Mercadante et al., 2009; de Graeff \& Dean, 2007; Seymour et al., 2007; Dean et al., 2014).

\section{LIMITATIONS}

This qualitative study included a small purposive sample of palliative care nurses practicing in one hospice unit. Nurses provide end-of-life care in multiple settings, and, as each setting has its unique characteristics, the results of our study do not reflect the experiences of all nurses caring for terminally patients and their families. Further, there were a number of challenges that were only touched on in the interviews and that require further exploration-for example, the concerns expressed by one of the more senior nurses regarding not being able to discuss treatment options with patients who had terminal restlessness.

\section{IMPLICATIONS FOR PRACTICE AND FUTURE RESEARCH}

Despite its limitations, there are a number of implications for practice and future research that emerge from our study. Primarily, hospice nurses need to be confident, competent, and well supported within an expert palliative care team when faced with making decisions about the use of palliative sedation. Although hospice palliative care is often carried out in a multi/interprofessional environment, discussions during team meetings do not always include staff at- titudes toward palliative sedation. Strong leadership is needed to facilitate a supportive culture where the complexity of dealing with ethical concerns is addressed. The importance of palliative care skills and the requirement that professionals be skilled in both symptom control and end-of-life care were identified in our study and are in keeping with contemporary research in the field. However, the part played by nurses in these processes is poorly understood. In addition, patient consent for terminal sedation has high priority in published guidelines, to the extent that recommendations are that terminal sedation should not be instigated under any condition where consent has not been obtained from the patient. The complexity of engaging in discussions with patients and their families from all angles, including gaining consent, requires further exploration.

\section{CONCLUSION}

Hospice nurses frequently encountered ethical and emotional dilemmas when making decisions about and administering palliative sedation. In the United Kingdom, a hospice nurse is frequently the primary clinician who engages in discussions about symptom management with patients and families and is also the clinician who administers the palliative sedation medication. Our study demonstrates that hospice nurses are regularly faced with the responsibility of making decisions about complex symptom management and medication regimes when administering palliative sedation. Making such decisions requires confidence on the part of the nurses as well as good communication and sound supportive teamwork within the hospice.

\section{REFERENCES}

Abarshi, E.A., Papavasiliou, E.S., Preston, N., et al. (2014). The complexity of nurses' attitudes and practice of sedation at the end of life: A systematic literature review. Journal of Pain and Symptom Management, 47, 915-925.

Beel, A., McClement, S.E. \& Harlos, M. (2002). Palliative sedation therapy: A review of definitions and usage. International Journal of Palliative Nursing, 8(4), 190-199.

Boston, P., Bruce, A. \& Schreibe, R. (2011). Existential suffering in the palliative care setting: An integrated literature review. Journal of Pain and Symptom Management, 41, 604-618.

Brajtman, S. (2003). The impact on the family of the terminal restlessness and its management. Palliative Medicine, 17, 454-460.

Brajtman, S. (2005). Terminal restlessness: Perspective of an interdisciplinary palliative care team. International Journal of Palliative Nursing, 11(4), 170-178.

Brajtman, S., Higuchi, K. \& McPherson, C. (2006). Caring for patients with terminal delirium: Palliative care unit 
and home care nurses' experiences. International Journal of Palliative Nursing, 12(4), 150-156.

Cheng, C., Roemer-Becuwe, C. \& Pereira, J. (2002). When midazolam fails. Journal of Pain and Symptom Management, 23(3), 256-265.

Cherny, N.I. \& Portenoy, R.K. (1994). Sedation in the treatment of refractory symptoms: Guidelines for evaluation and treatment. Journal of Palliative Care, 10, 31-38.

Cherny, N.L. \& Radbruch, L. (2009). European Association for Palliative Care (EAPC) recommended framework for the use of sedation in palliative care. Palliative Medicine, 23(7), 581-593.

Claessens, P., Menten, J., Schotsmans, P., et al. (2008). Palliative sedation: A review of the research literature. Journal of Pain and Symptom Management, 36, 310-333.

Claessens, P., Menten, J., Schotsmans, P., et al. (2011). Palliative sedation, not slow euthanasia: A prospective, longitudinal study of sedation in Flemish palliative care units. Journal of Pain and Symptom Management, 41, $14-24$.

Colaizzi, P. (1978). Psychological research as the phenomenologist views it. In Existential-phenomenological alternatives for psychology. R. Valle \& M. King (eds.), pp. 48-71. New York: Oxford University Press.

Creswell, J.W. (2009). Research design: Qualitative, quantitative and mixed-methods approaches, 3rd ed. Thousand Oaks, CA: Sage.

Dean, A., Miller, B. \& Woodwark, C. (2014). Sedation at the end of life: A hospice's decision-making practices in the U.K. International Journal of Palliative Nursing, 20(10), 474-481.

de Graeff, A. \& Dean, M. (2007). Palliative sedation therapy in the last weeks of life: A literature review and recommendations for standards. Journal of Palliative Medicine, 10, 67-85.

De Witt, L. \& Ploeg, J. (2006). Critical appraisal of rigour in interpretive phenomenological nursing research. Journal of Advanced Nursing, 55(2), 215-229.

Engström, J., Bruno, E., Holm, B., et al. (2006). Palliative sedation at end of life: A systematic literature review. European Journal of Oncology Nursing, 11, 26-35.

Fainsinger, R., DeMoissac, D. \& Oneschuk, D., (2000). Sedation for delirium and other symptoms in terminally ill patients in Edmonton. Journal of Palliative Care, 16(2), 5-10.

Fillion, L., Tremblay, I., Truchon, M., et al. (2007). Job satisfaction and emotional distress among nurses providing palliative care: Empirical evidence for an integrative occupational stress-model. International Journal of Stress Management, 14(1), 1-25.

Gillon, S., Johnson, M. \& Campbell, C. (2010). Review of phenobarbitone use for deep terminal sedation in a U.K. hospice. Palliative Medicine, 24(1), 100-101.

Goldsteen, M., Houtepen, R., Proot, I.M., et al. (2006). What is a good death? Terminally ill patients dealing with normative expectations around death and dying. Patient Education and Counseling, 64(3), 378-386.

Guest, G., Bunce, A. \& Johnson, L. (2006). How many interviews are enough? An experiment with data saturation and variability. Field Methods, 18, 59-82.

Hallenbeck, J.L. (2000). Terminal sedation: Ethical implications in different situations. Journal of Palliative Medicine, 3, 313-319.

Hart, B., Sainsbury, P. \& Short, S. (1998). Whose dying? A sociological critique of the "good death." Mortality, 3(1), $65-77$.
Hauser, K. \& Walsh, D. (2009). Palliative sedation: Welcome guidance on a controversial issue. Palliative Medicine, 23(7), 577-579.

Heidegger, M. (1962). Being and time. Oxford: Blackwell Publishing.

Inghelbrecht, E., Bilsen, J., Mortier, F., et al. (2011). Continuous deep sedation until death in Belgium: A survey among nurses. Journal of Pain and Symptom Management, 41, 870-879.

Kirklin, D. (2010). The role of humanities in palliative care. In Oxford textbook of palliative medicine, 4th ed. G. Hanks et al. (eds.), pp. 1603-1612. Oxford: Oxford University Press.

Koch, T. (1995). Interpretative approaches in nursing research: The influence of Husserl and Heidegger. Journal of Advanced Nursing, 21(5), 827-836.

Kohara, H., Ueoka, H., Takeyama, H., et al. (2005). Sedation for terminally ill patients with cancer with uncontrollable physical distress. Journal of Palliative Medicine, 8(1), 20-25.

Kulbe, J. (2001). Stressors and coping measures of hospice nurses. Home Healthcare Nurse, 19(11), 707-711.

Lavoie, M., Blondeau, D. \& De Koninck, T. (2008). The dying person: An existential being until the end of life. Nursing Philosophy, 9, 89-97.

Legemaate, J., Verkerk, M., van Wijlick, E., et al. (2007). Palliative sedation in the Netherlands (2007): Starting-points and contents of a national guideline. European Journal of Health Law, 14, 61-73.

Lopez, K.A. \& Willis, D.G. (2004). Descriptive versus interpretive phenomenology: Their contributions to nursing knowledge. Qualitative Health Research, 14, 726-735.

Low, J.T. \& Payne, S. (1996). The good and bad death perceptions of health professionals working in palliative care. European Journal of Cancer Care, 5(4), 237-241.

Materstvedt, L.J. \& Bosshard, G. (2009). Deep and continuous palliative sedation (terminal sedation): Clinicalethical and philosophical aspects. The Lancet Oncology, 10(6), 622-627.

McNamara, B. (2004). Good enough death: Autonomy and choice in Australian palliative care. Social Science \& Medicine, 58, 929-938.

Mercadante, S., Intravaia, G., Villari, P., et al. (2009). Controlled sedation for refractory symptoms in dying patients. Journal of Pain and Symptom Management, $37(5), 771-779$.

Morita, T. (2004). Palliative sedation to relieve psycho-existential suffering of terminally ill cancer patients. Journal of Pain and Symptom Management, 28(5), 445-450.

Morita, T., Tei, Y. \& Inoue, S. (2003). Ethical validity of palliative sedation therapy. Journal of Pain and Symptom Management, 25, 103-105.

Morita, T., Miyashita, M., Kimura, R., et al. (2004). Emotional burden of nurses in palliative sedation therapy. Palliative Medicine, 18, 550-557.

Morita, T., Chinone, Y., Ikenaga, M., et al. (2005). Ethical validity of palliative sedation therapy: A multicenter, prospective, observational study conducted on specialized palliative care units in Japan. Journal of Pain and Symptom Management, 30, 308-319.

Nilsson, A. \& Tengvall, C. (2013). One last opportunity: Swedish nurses' experiences of palliative sedation. Journal of Hospice \& Palliative Nursing, 15(6), E1-E5.

Patton, M.Q. (2002). Qualitative research and evaluation, 3rd ed. Thousand Oaks, CA: Sage.

Parahoo, K. (2006). Nursing research: Principles, process and issues, 3rd ed. Basingstoke: Palgrave Macmillan. 
Raus, K., Brown, J., Seale, C., et al. (2014). Continuous sedation until death: The everyday moral reasoning of physicians, nurses and family caregivers in the U.K., the Netherlands and Belgium. BMC Medical Ethics, 15, 14. Available from http://www.biomedcentral.com/ $1472-6939 / 15 / 14$.

Rietjens, J., van Delden, J., Onwuteaka-Philipsen, B., et al. (2008). Continuous deep sedation for patients nearing death in the Netherlands: Descriptive study. British Medical Journal, 336(7648), 810-813.

Rietjens, J.A.C., Hauser, J., van der Heibe, A., et al. (2007). Having a difficult time leaving: Experiences and attitudes of nurses with palliative sedation. Palliative Medicine, 21(7), 643-649.

Scarre, G. (2012). Can there be a good death? Journal of Evaluation in Clinical Practice, 18(5), 1082-1086.

Schildmann, E. \& Schildmann, J. (2014). Palliative sedation therapy: A systematic literature review and critical appraisal of available guidance on indication and decision making. Journal of Palliative Medicine, 17(5), 601-611.
Seale, C. (2009). Continuous deep sedation in U.K. medical practice: Descriptive study. Journal of Pain and Symptom Management, 39(1), 44-53.

Seymour, J.E., Janssens, R. \& Broeckaert, B. (2007). Relieving suffering at the end of life: Practitioners' perspectives on palliative sedation from three European countries. Social Science \& Medicine, 64(8), 1679-1691.

Swart, S.J., Rietjens, J.A.C., van Zuylen, L., et al. (2012). Continuous palliative sedation for cancer and noncancer patients. Journal of Pain and Symptom Management, 43(2), 172-180.

Verkerk, M., van Wijlick, E., Legemaate, J., et al. (2007). A national guideline for palliative sedation in the Netherlands. Journal of Pain and Symptom Management, 34, $666-670$

Watson, M., Lucas, C., Hoy, A., et al. (2009). Oxford handbook of palliative care. Oxford: Oxford University Press.

Zinn, C.L. \& Moriarty, D. (2012). Nurses' perceptions of palliative sedation in a Scottish hospice: An exploratory study. Journal of Hospice \& Palliative Nursing, 14(5), $358-364$ 